\title{
The impact of ribavirin on real-world adherence rates in hepatitis $C$ patients treated with sofosbuvir plus simeprevir
}

This article was published in the following Dove Press journal:

ClinicoEconomics and Outcomes Research

17 December 2015

Number of times this article has been viewed

\section{David R Walker \\ Timothy R Juday \\ Shivaji R Manthena \\ Yonghua Jing \\ Vipan Sood}

Health Economics and Outcomes Research, AbbVie Inc., North Chicago, IL, USA

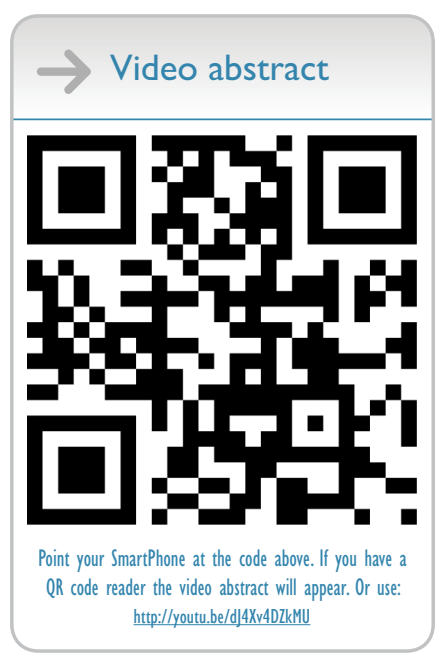

Correspondence:Timothy R Juday Health Economics and Outcomes Research, AbbVie Inc., I North Waukegan Road, AP3I-0I Department GMHI, Chicago, IL, 60064, USA

$\mathrm{Tel}+18479351616$

Fax + I 8479373440

Email timothy.juday@abbvie.com
Background: Combination therapy with sofosbuvir (SOF) and simeprevir (SIM) is used to treat patients with hepatitis $\mathrm{C}$ virus infection. It is currently unknown whether adding ribavirin (RBV) to SOF + SIM, which raises the pill count from two up to eight pills a day, impacts adherence. The aim of this study is to examine the impact of pill count on real-world adherence rates in patients treated with SOF + SIM with and without RBV.

Methods: This retrospective study assessed composite adherence to SOF and SIM over 12 weeks of treatment for two cohorts of hepatitis C patients: one initiating SOF + SIM therapy, and the other initiating SOF + SIM + RBV therapy. Analyses were conducted using MarketScan ${ }^{\circledR}$ and Optum US commercial pharmacy claims and enrollment data. Adherence was adjusted by treatment regimen, age, sex, co-pay, presence/absence of cirrhosis, treatment history, and Charlson Comorbidity Index.

Results: There was a significant difference in composite unadjusted and adjusted adherence rates for SOF and SIM for the SOF + SIM vs SOF + SIM + RBV cohorts based on MarketScan data (unadjusted, $92.6 \%$ and $89.7 \%$, respectively; $P=0.0423$; adjusted, $92.2 \%$ and $88.7 \%$, respectively; $P=0.0176$ ), but not based on Optum data (unadjusted, $94.8 \%$ and $95.6 \%$, respectively; $P=0.5618$; adjusted, $94.8 \%$ and $95.1 \%$, respectively; $P=0.8589$ ). In the MarketScan and Optum databases, there were no statistical differences in unadjusted and adjusted adherence rates for SOF. Unadjusted and adjusted adherence rates for SIM were mixed, as they were for composite adherence.

Conclusion: The impact of the addition of RBV to SOF + SIM therapy was mixed. The impact of RBV on SOF adherence was not significant in either database.

Keywords: adherence, hepatitis $\mathrm{C}$, direct acting antiviral, sofosbuvir, simeprevir, ribavirin

\section{Introduction}

Chronic hepatitis $\mathrm{C}$ virus ( $\mathrm{HCV}$ ) infection is a global health problem that can lead to long-term sequelae, including hepatocellular carcinoma and cirrhosis of the liver. ${ }^{1,2}$ The prevalence of chronic HCV infection in the US is estimated to be between 2.7 and 5.2 million people, ${ }^{3,4}$ making $\mathrm{HCV}$ the most common bloodborne infection in the US. Some treatment patterns in the US include the use of various direct-acting antivirals (DAAs), including sofosbuvir (SOF), typically given for 12 to 24 weeks, and simeprevir (SIM), typically given for 12 weeks..$^{5-7}$ Recently, the combination SOF + SIM regimen was approved for the treatment of chronic HCV genotype 1 infection, based on the results of the COSMOS trial..$^{8,9}$ The recommended dosage and treatment duration for treatment-naïve and treatment-experienced patients without cirrhosis is 12 weeks of SOF + SIM, and 24 weeks for treatment-naïve and treatment-experienced patients with cirrhosis. ${ }^{10}$ 
Therapeutic intervention is essential, as successful antiHCV therapy (defined as sustained virologic response [SVR]) can halt disease progression. ${ }^{11}$ Evidence from interferonbased therapies suggests that SVR rates depend on the level of adherence to therapy. McHutchison et $\mathrm{a}^{12}$ demonstrated that SVR rates increased significantly when patients had adherence rates $\geq 80 \%$ (from $44 \%$ to $52 \%, P=0.0018$, for interferon [IFN] + RBV therapy, and from $54 \%$ to $63 \%$, $P=0.01$, for peg-IFN + RBV therapy).

The combination of SOF + SIM has been used in the US with or without RBV to treat patients with HCV. To date, a single clinical trial, the COSMOS study, ${ }^{8,9}$ has reported discontinuation rates for this combination therapy. Evidence reporting adherence rates for treatment with SOF + SIM is limited. The COSMOS study was a randomized, multicenter, open-label trial that investigated the efficacy of SOF + SIM, with or without $\mathrm{RBV}$, in patients with chronic HCV genotype 1 infections over 12 and 24 weeks. ${ }^{8}$ Treatment discontinuation, recorded as the proportion of patients who either stopped treatment due to adverse events, were lost to follow-up, or withdrew voluntarily, was $0 \%$ for patients treated with SOF + SIM for 12 weeks, $0 \%$ for patients treated with SOF +SIM + RBV for 12 weeks, $6 \%$ for patients treated with SOF + SIM for 24 weeks, and $6 \%$ for patients treated with SOF + SIM + RBV for 24 weeks. ${ }^{12}$

A recent analysis of real-world data in the US by CVS Health found a four-fold increase in the discontinuation of SOF-based regimens compared to the discontinuation rate published in clinical trials. ${ }^{13}$ The CVS Health analysis, however, did not examine whether the addition of RBV to SOF + SIM, which raises the pill count of the regimen from two pills (two pills once a day) to up to eight pills (two pills once a day plus three pills twice a day), had an impact on adherence to SOF + SIM treatment. The objective of the retrospective analysis was to assess the effect of pill burden on real-world adherence rates for SOF and SIM for HCV patients initiating $\mathrm{SOF}+\mathrm{SIM}$ or $\mathrm{SOF}+\mathrm{SIM}+\mathrm{RBV}$ treatment regimens.

\section{Methods}

\section{Data source}

The study sample was selected from the Truven Health MarketScan ${ }^{\circledR}$ commercial claims and encounters database and from the OptumInsight (Optum) Clinformatics ${ }^{\mathrm{TM}}$ database. The MarketScan database includes records of prescription drug claims of nearly 31 million commercially insured enrollees from the US. The Optum database contains patientlevel data, including pharmacy claims data, from enrollees in managed care plans administered by United Health Group. All database records are de-identified and fully compliant with US patient confidentiality requirements. The data used in our present analysis included US commercial enrollment and pharmacy files from the period covering January 2006 through December 2014. All currency is reported in 2014 US dollars.

\section{Inclusion and exclusion criteria}

Patients were included in the study if they had an HCV diagnosis code (International Classification of Diseases, 9th Revision, Clinical Modification [ICD-9-CM]) prior to index date and had initiated treatment with SOF + SIM or SOF + SIM + RBV between December 2013 and July 8 (Optum) or September 30 (MarketScan), 2014, and if they had a minimum of 6 months continuous enrollment prior to the index date and continuous enrollment from the month of index date (defined as the first fill date for SOF) through the following 3 months. The SIM and/or RBV medications had to have been initiated within 14 days pre- or post-index date of SOF. Patients were excluded from the study if they received an 84-day supply of SOF on initial fill.

\section{Analyses}

This study retrospectively analyzed adherence rates for SOF and SIM for HCV patients in the US who met the previously defined inclusion and exclusion criteria, starting on the index date and over the following 12 weeks ( 84 days). It should be noted that although some patients may have been treated with SOF + SIM for longer than 12 weeks, we examined only the first 12 weeks in our analysis. Composite adherence for SOF and SIM was defined as the total number of days of supply for SOF and SIM available during the first 84 days of treatment/ the number of days in the study for SOF and SIM $(168) \times 100$. Adherence for SOF was defined as the number of SOF tablets available over 12 weeks of treatment ( 84 days) divided by 84 . Adherence for SIM was defined as the number of SIM tablets available over 12 weeks of treatment ( 84 days) divided by 84. Only adherence to the DAA therapies was investigated, as adherence to RBV may be effected by factors, such as dosing and sample pills.

Statistical analyses were conducted using population proportion $z$-tests. Generalized linear modeling was used to adjust adherence by treatment regimen, age, sex, copay, presence/absence of cirrhosis (determined by Current Procedural Terminology codes and ICD-9-CM procedure codes), treatment history, and Charlson Comorbidity Index (CCI). Analyses were undertaken using $\mathrm{SAS}^{\circledR} 9.3$ software. Significance between the SOF + SIM and SOF + SIM + RBV cohorts was defined as a $P$-value $<0.05$. 


\section{Results}

A total of 5,799 patients from the MarketScan database were identified as having at least one SOF prescription initiated between December 2013 and September 2014. A total of 910 patients met the pre-specified inclusion criteria, of which 788 patients made up the SOF + SIM cohort, while 122 patients made up the SOF + SIM + RBV cohort. From the Optum database, 1,900 patients were identified as having at least one SOF prescription initiated between December 2013 and July 8, 2014. The pre-specified inclusion criteria were met by 519 patients, of which 440 made up the SOF + SIM cohort and 79 made up the SOF + SIM + RBV cohort. Detailed information on patient attrition at each step in the sample selection process has been provided in Tables 1 and 2, and patient demographics are shown in Tables 3 and 4 . There were no significant differences between cohorts in age (56.8 \pm 6.9 years vs $56.7 \pm 6.9$ years for the SOF + SIM and the SOF + SIM + RBV cohorts, respectively; $P=0.8815)$ and sex $(65.4 \%$ male vs $72.1 \%$ male for the SOF + SIM and the $\mathrm{SOF}+\mathrm{SIM}+\mathrm{RBV}$ cohorts, respectively; $P=0.1506)$ from the MarketScan database. There were no significant differences between cohorts in age $(56.8 \pm 6.9$ years vs $56.7 \pm 6.9$ years for the SOF + SIM and the SOF + SIM + RBV cohorts, respectively; $P=0.8815)$ and gender $(65.4 \%$ male vs $72.1 \%$ male for the SOF + SIM and the SOF + SIM + RBV cohorts, respectively; $P=0.1506$ ) from the MarketScan database. There were significant differences between cohorts in age (57.3 \pm 7.6 years vs $55.1 \pm 7.8$ years for the SOF + SIM and the SOF + SIM + RBV cohorts, respectively; $P=0.0187$ ) but not in gender $(63.6 \%$ male vs $65.8 \%$ male for the SOF + SIM

Table I MarketScan ${ }^{\circledR}$ database: patient attrition

\begin{tabular}{|c|c|c|}
\hline & $\begin{array}{l}\text { Patients } \\
\text { excluded }\end{array}$ & $\begin{array}{l}\text { Patients } \\
\text { remaining }\end{array}$ \\
\hline $\begin{array}{l}\text { Number of patients with at least one } \\
\text { sofosbuvir prescription initiated from } \\
\text { December } 2013 \text { to September } 2014\end{array}$ & 0 & 5,779 \\
\hline Attrition reason & & \\
\hline $\begin{array}{l}\text { Number of patients on sofosbuvir and } \\
\text { simeprevir from December } 2013 \text { to } \\
31 \text { September } 2014\end{array}$ & 4,059 & $\mathrm{I}, 720$ \\
\hline $\begin{array}{l}\text { At least } 6 \text { months of pre-index and } \\
12 \text { weeks of post-index eligibility }\end{array}$ & 731 & 989 \\
\hline $\begin{array}{l}\text { Delete patients who did not have } \\
\mathrm{HCV} \text { diagnosis before index date }\end{array}$ & 47 & 942 \\
\hline Delete patients who had $\geq 84$ days of supply & 32 & 910 \\
\hline $\begin{array}{l}\text { Number of patients in cohort } \\
\text { sofosbuvir + simeprevir }\end{array}$ & 0 & 788 \\
\hline $\begin{array}{l}\text { Number of patients in cohort } \\
\text { sofosbuvir }+ \text { simeprevir + ribavirin }\end{array}$ & 0 & 122 \\
\hline
\end{tabular}

Abbreviation: $\mathrm{HCV}$, hepatitis $\mathrm{C}$ virus.
Table 2 Optum database: patient attrition

\begin{tabular}{|c|c|c|}
\hline & $\begin{array}{l}\text { Patients } \\
\text { excluded }\end{array}$ & $\begin{array}{l}\text { Patients } \\
\text { remaining }\end{array}$ \\
\hline $\begin{array}{l}\text { Number of patients with at least one } \\
\text { sofosbuvir prescription initiated from }\end{array}$ & & 1,900 \\
\hline December 2013 to July 8,2014 & & \\
\hline Attrition reason & & \\
\hline $\begin{array}{l}\text { Number of patients on sofosbuvir and } \\
\text { simeprevir from December } 2013 \text { to } \\
\text { Sep 3I, 20I4 }\end{array}$ & $|, 26|$ & 639 \\
\hline At least 6 months of pre-index and & 117 & 522 \\
\hline 12 weeks of post-index eligibility & & \\
\hline Delete patients who did not have & 3 & 519 \\
\hline HCV diagnosis before index date & & \\
\hline Delete patients who had $\geq 84$ days of supply & 0 & 519 \\
\hline $\begin{array}{l}\text { Number of patients in cohort } \\
\text { sofosbuvir + simeprevir }\end{array}$ & & 440 \\
\hline $\begin{array}{l}\text { Number of patients in cohort } \\
\text { sofosbuvir + simeprevir + ribavirin }\end{array}$ & & 79 \\
\hline
\end{tabular}

Abbreviation: $\mathrm{HCV}$, hepatitis $\mathrm{C}$ virus.

and the SOF + SIM + RBV cohorts, respectively; $P=0.7993$ ) from the Optum database.

Significant differences were observed between cohorts for both databases regarding co-pay category distributions. The percentage of cirrhotic and treatment-experienced patients were significantly higher in the SOF + SIM + RBV vs the $\mathrm{SOF}+$ SIM cohorts from the MarketScan database (cirrhosis, $56.6 \%$ vs $42.8 \%$, respectively; $P=0.0046$; treatmentexperienced, $16.4 \%$ vs $9.9 \%$, respectively; $P=0.0403$ ), but there was no significant difference in mean Charlson score. The percentage of cirrhotic patients was significantly higher

Table 3 Baseline characteristics of patients from the MarketScan ${ }^{\circledR}$ database

\begin{tabular}{|c|c|c|c|}
\hline Variables & $\begin{array}{l}\text { SOF + SIM } \\
(n=788)\end{array}$ & $\begin{array}{l}\text { SOF + SIM + RBV } \\
(n=\mid 22)\end{array}$ & $P$-value \\
\hline Age, mean (SD) & $56.8(6.9)$ & $56.7(6.9)$ & 0.8815 \\
\hline Sex, $\%$ male & $65.4 \%$ & $72.1 \%$ & 0.1506 \\
\hline $\begin{array}{l}\text { Co-pay, mean (SD), } \\
\text { median }\end{array}$ & $\begin{array}{l}\$ 199.50 \\
(602.2), \$ 80\end{array}$ & $\begin{array}{l}\$ 337.70 \\
(1,447.8), \$ 107.5\end{array}$ & 0.0656 \\
\hline \multicolumn{4}{|l|}{ Co-pay category } \\
\hline$\$ 0-\$ 25(\%)^{*}$ & $21.6 \%$ & $15.6 \%$ & N/A \\
\hline$\$ 26-\$ 50(\%)^{*}$ & $14.1 \%$ & $4.1 \%$ & $N / A$ \\
\hline$\$ 5 \mathrm{I}-\$ 100(\%)^{*}$ & $28.3 \%$ & $27.9 \%$ & $\mathrm{~N} / \mathrm{A}$ \\
\hline$>\$ 100(\%)^{*}$ & $36.0 \%$ & $52.5 \%$ & $N / A$ \\
\hline Cirrhosis, \% & $42.8 \%$ & $56.6 \%$ & 0.0046 \\
\hline $\begin{array}{l}\text { Treatment } \\
\text { experienced, \% }\end{array}$ & $9.9 \%$ & $16.4 \%$ & 0.0403 \\
\hline Charlson & $2.7 \mathrm{I}(2.83)$ & $2.72(2.91)$ & 0.9711 \\
\hline $\begin{array}{l}\text { Comorbidity Index, } \\
\text { mean (SD) }\end{array}$ & & & \\
\hline
\end{tabular}


Table 4 Baseline characteristics of patients from the Optum database

\begin{tabular}{|c|c|c|c|}
\hline Variables & $\begin{array}{l}\text { SOF + SIM } \\
(n=440)\end{array}$ & $\begin{array}{l}\text { SOF + SIM + RBV } \\
(n=79)\end{array}$ & $P$-value \\
\hline Age, mean (SD) & $57.3(7.6)$ & $55.1(7.8)$ & 0.0187 \\
\hline Sex, \% male & $63.6 \%$ & $65.8 \%$ & 0.7993 \\
\hline $\begin{array}{l}\text { Co-pay, mean (SD), } \\
\text { median }\end{array}$ & $\begin{array}{l}\$ 346 \\
(1,009), \$ 95\end{array}$ & $\begin{array}{l}\$ 404 \\
(1,306), \$ 110\end{array}$ & 0.6542 \\
\hline \multicolumn{4}{|l|}{ Co-pay category } \\
\hline$\$ 0-\$ 25(\%)^{*}$ & $5.2 \%$ & $3.8 \%$ & $\mathrm{~N} / \mathrm{A}$ \\
\hline$\$ 26-\$ 50(\%)^{*}$ & $3.4 \%$ & $0.0 \%$ & $\mathrm{~N} / \mathrm{A}$ \\
\hline$\$ 5 \mathrm{I}-\$ 100(\%)^{*}$ & $55.7 \%$ & $29.1 \%$ & $\mathrm{~N} / \mathrm{A}$ \\
\hline$>\$ 100(\%)^{*}$ & $35.7 \%$ & $67.1 \%$ & $\mathrm{~N} / \mathrm{A}$ \\
\hline Cirrhosis, \% & $42.5 \%$ & $55.7 \%$ & 0.0363 \\
\hline $\begin{array}{l}\text { Treatment } \\
\text { experienced, \% }\end{array}$ & $12.5 \%$ & $13.9 \%$ & 0.7149 \\
\hline Charlson & $2.67(2.96)$ & $2.48(2.65)$ & 0.5940 \\
\hline \multicolumn{4}{|l|}{ Comorbidity } \\
\hline
\end{tabular}

Notes: *Overall distributional differences between the cohorts; $P<0.05$. All currency is in 2014 USD.

Abbreviations: SOF, sofosbuvir; SIM, simeprevir; RBV, ribavirin; SD, standard deviation.

in the $\mathrm{SOF}+\mathrm{SIM}+\mathrm{RBV}$ vs the $\mathrm{SOF}+\mathrm{SIM}$ cohorts from the Optum database (55.7\% vs $42.5 \%$, respectively; $P=0.0363$ ), but there were no significant differences in the percentage of treatment-experienced patients and the mean Charlson score (Tables 3 and 4).

Based on MarketScan commercial pharmacy claims and enrollment data, a significant difference was observed in unadjusted composite adherence rates for SOF and SIM $(92.6 \%$ for the SOF + SIM cohort vs $89.7 \%$ for the SOF + $\mathrm{SIM}+\mathrm{RBV}$ cohort; $P=0.0423$ ) and in adjusted composite adherence rates for SOF and SIM $(92.2 \%$ for the SOF + SIM cohort vs $88.7 \%$ for the SOF + SIM +RBV cohort; $P=0.0176$ ) (Table 5).
Based on Optum commercial pharmacy claims and enrollment data, no differences were observed between the two cohorts in unadjusted composite adherence rates for SOF and SIM (94.8\% for the SOF + SIM cohort vs $95.6 \%$ for the $\mathrm{SOF}+\mathrm{SIM}+\mathrm{RBV}$ cohort; $P=0.5618)$, or in the adjusted composite adherence rates for SOF and SIM (94.8\% for the SOF + SIM cohort vs $95.1 \%$ for the SOF + SIM + RBV cohort; $P=0.8589$ ) (Table 5).

In the MarketScan and Optum databases, there were no statistical differences in unadjusted (MarketScan: $92.6 \%$ for the SOF + SIM cohort vs $90.2 \%$ for the SOF + SIM + RBV cohort; $P=0.1101$; Optum: $94.8 \%$ for the SOF + SIM cohort vs $95.6 \%$ for the SOF + SIM + RBV cohort; $P=0.5488$ ) and adjusted (MarketScan: $92.2 \%$ for the SOF + SIM cohort vs $89.3 \%$ for the SOF + SIM + RBV cohort; $P=0.0514$; Optum: $94.8 \%$ for the SOF + SIM cohort vs $95.1 \%$ for the SOF + $\mathrm{SIM}+\mathrm{RBV}$ cohort; $P=0.8409$ ) adherence rates for SOF. Unadjusted and adjusted adherence rates for SIM were mixed, as they were for composite adherence rate.

Generalized linear modeling showed that treatment regimen, age, and some co-pay categories (\$0-\$25, \$26-\$50) had a significant influence on adherence in patients enrolled in the MarketScan database (Tables 6 and 7).

\section{Discussion}

To the best of our knowledge, this study is the first to assess the impact of pill burden on real-world adherence rates for SOF and SIM among HCV patients initiating therapy with SOF + SIM. Our study demonstrated that adding RBV to SOF + SIM therapy, which increased the daily pill burden, had an impact on composite adherence for SOF and SIM in patients enrolled in the MarketScan database, but not for patients enrolled in

Table 5 Composite adherence rates for patients treated with SOF + SIM or SOF + SIM + RBV from the MarketScan ${ }^{\circledR}$ or Optum database

\begin{tabular}{|c|c|c|c|c|c|c|}
\hline & \multicolumn{3}{|c|}{ Unadjusted adherence rates } & \multicolumn{3}{|c|}{ Adjusted adherence rates } \\
\hline & SOF + SIM & SOF + SIM + RBV & $P$-value & SOF + SIM & SOF + SIM + RBV & $P$-value \\
\hline \multicolumn{7}{|l|}{ MarketScan ${ }^{\circledR}$} \\
\hline Number of patients in cohort & $\mathrm{n}=788$ & $n=122$ & $\mathrm{~N} / \mathrm{A}$ & $\mathrm{n}=788$ & $n=122$ & $\mathrm{~N} / \mathrm{A}$ \\
\hline Adherence rate for SOF & $92.6 \%$ & $90.2 \%$ & 0.1101 & $92.2 \%$ & $89.3 \%$ & 0.0514 \\
\hline Adherence rate for SIM & $92.6 \%$ & $89.1 \%$ & 0.0153 & $92.2 \%$ & $88.1 \%$ & 0.0058 \\
\hline $\begin{array}{l}\text { Composite adherence rate } \\
\text { for SOF and SIM }\end{array}$ & $92.6 \%$ & $89.7 \%$ & 0.0423 & $92.2 \%$ & $88.7 \%$ & 0.0176 \\
\hline \multicolumn{7}{|l|}{ Optum } \\
\hline Number of patients in cohort & $\mathrm{n}=440$ & $\mathrm{n}=79$ & $\mathrm{~N} / \mathrm{A}$ & $\mathrm{n}=440$ & $\mathrm{n}=79$ & $\mathrm{~N} / \mathrm{A}$ \\
\hline Adherence rate for SOF & $94.8 \%$ & $95.6 \%$ & 0.5488 & $94.8 \%$ & $95.1 \%$ & 0.8409 \\
\hline Adherence rate for SIM & $94.8 \%$ & $95.6 \%$ & 0.5755 & $94.8 \%$ & $95.1 \%$ & 0.8772 \\
\hline $\begin{array}{l}\text { Composite adherence rate } \\
\text { for SOF and SIM }\end{array}$ & $94.8 \%$ & $95.6 \%$ & 0.5618 & $94.8 \%$ & $95.1 \%$ & 0.8589 \\
\hline
\end{tabular}

Abbreviations: SOF, sofosbuvir; SIM, simeprevir; RBV, ribavirin; SD, standard deviation. 
Table 6 MarketScan ${ }^{\circledR}$ database: generalized linear model results for calculating composite adjusted adherence rates*

\begin{tabular}{|c|c|c|c|c|}
\hline Parameter & Estimate & Standard error & $P$-value & Interpretation \\
\hline Intercept & 0.8291 & 0.0452 & $<0.001$ & $\mathrm{~N} / \mathrm{A}$ \\
\hline $\mathrm{SOF}+\mathrm{SIM}+\mathrm{RBV}$ & -0.0333 & 0.0146 & 0.0230 & $\begin{array}{l}\text { SOF + SIM + RBV had } 3.3 \% \text { lower } \\
\text { adherence than SOF + SIM }\end{array}$ \\
\hline Female sex & 0.0002 & 0.0105 & 0.9854 & Not significant \\
\hline Age, years & 0.0017 & 0.0007 & 0.0162 & $\begin{array}{l}\text { For every I year increase in age, } \\
\text { adherence increased by } 0.17 \%\end{array}$ \\
\hline Co-pay $\$ 0-\$ 25$ & -0.0320 & 0.0134 & 0.0174 & $\begin{array}{l}\text { Compared to a co-pay }>\$ 100 \text {, a co-pay } \\
\text { of } \$ 0-\$ 25 \text { had a } 3.1 \% \text { lower adherence }\end{array}$ \\
\hline Co-pay $\$ 26-\$ 50$ & -0.0335 & 0.0160 & 0.0364 & $\begin{array}{l}\text { Compared to a co-pay }>\$ 100 \text {, a co-pay } \\
\text { of } \$ 26-\$ 50 \text { had a } 3.3 \% \text { lower adherence }\end{array}$ \\
\hline Co-pay $\$ 5 I-\$ 100$ & -0.0183 & 0.0122 & 0.1337 & Not significant \\
\hline Charlson Comorbidity Index & -0.0018 & 0.0018 & 0.3160 & Not significant \\
\hline No cirrhosis & -0.0017 & 0.0101 & 0.8641 & Not significant \\
\hline Treatment-naïve & 0.0236 & 0.0159 & 0.1375 & Not significant \\
\hline
\end{tabular}

Notes: *Similar findings for SIM only and SOF only. All currency is in 2014 USD.

Abbreviations: SOF, sofosbuvir; SIM, simeprevir; RBV, ribavirin; N/A, not applicable.

the Optum database. The reasons for the conflicting results obtained from the two patient cohorts are unclear. SOF + SIM is a short-term $\mathrm{HCV}$ treatment regimen. Observations from a recent study comparing adherence to three antiviral regimens, composed of 1, 2, and 3 pills daily in the first 12 weeks of HIV therapy, suggest that pill count does not impact antiviral medication adherence over the initial 12 weeks of treatment. ${ }^{14}$ Therefore, increased pill burden is not expected to have a substantial impact on real-world composite adherence rates for SOF and SIM. Furthermore, adding RBV to SOF + SIM therapy had no impact on adherence rates for SOF in patients enrolled in both the MarketScan and Optum databases. More studies are required to understand the possible impact of pill count and RBV on adherence to a short-term HCV regimen.

Importantly, overall adherence rates were high for both cohorts, with all adherence rates being $>80 \%$. These data

Table 7 Optum database: generalized linear model results for calculating composite adjusted adherence rates*

\begin{tabular}{lllll}
\hline Parameter & Estimate & $\begin{array}{l}\text { Standard } \\
\text { error }\end{array}$ & P-value & Interpretation \\
\hline Intercept & 0.9643 & 0.0442 & $<0.0001$ & N/A \\
SOF + SIM + RBV & 0.0027 & 0.0150 & 0.8589 & Not significant \\
Female sex & -0.0027 & 0.0110 & $0.805 I$ & Not significant \\
Age, years & 0.0004 & 0.0007 & 0.6063 & Not significant \\
Co-pay $\$ 0-\$ 25$ & -0.0142 & 0.0251 & 0.5725 & Not significant \\
Co-pay $\$ 26-\$ 50$ & -0.0543 & 0.0319 & 0.0887 & Not significant \\
Co-pay $\$ 5 I-\$ 100$ & -0.0156 & 0.0112 & 0.1633 & Not significant \\
Charlson & 0.0001 & 0.0019 & 0.9542 & Not significant \\
Comorbidity Index & & & & \\
No cirrhosis & 0.0014 & 0.0112 & 0.9031 & Not significant \\
Treatment-naïv & -0.0295 & 0.0157 & 0.0611 & Not significant \\
\hline
\end{tabular}

Notes: *Similar findings for SIM only and SOF only. All currency is in 2014 USD. Abbreviations: SOF, sofosbuvir; SIM, simeprevir; RBV, ribavirin; N/A, not applicable. are promising, as good adherence to therapy is associated with virologic cure in patients with $\mathrm{HCV} .{ }^{12}$ The observations may have implications for other HCV therapies that require combination therapy with RBV. However, it is not known what adherence level is critical for achieving SVR in these new SOF-based regimens.

RBV has been part of the standard of care for chronic $\mathrm{HCV}$ infection for the last 10 years. ${ }^{15}$ The addition of RBV to $\mathrm{HCV}$ therapies is thought to reduce viral breakthroughs and relapses, particularly among patients with genotype $1 \mathrm{a}$ $\mathrm{HCV}$ infection. ${ }^{16}$ To date, the mechanism of action of RBV is not well understood. Evidence from the literature suggests several possibilities, including that 1) RBV may have a direct antiviral effect against the HCV virus; 2) RBV may alter the $\mathrm{T}$ helper cytokine balance from an anti-inflammatory Th2 profile to a pro-inflammatory Th1 profile; and 3) RBV may lead to production of virus with reduced infectivity. ${ }^{16}$ Previous studies suggest that there is evidence to support the role of RBV in combination with current HCV therapies; however, the role of RBV in future HCV therapies requires further investigation. ${ }^{16}$

The strengths of the current study were that it analyzed a national sample of $\mathrm{HCV}$-infected individuals from two large health care claims databases and that it was conducted in a real-world setting. Claims data can facilitate effective examination of health care outcomes, treatment patterns, and costs. However, they are not purposely designed for such research. Therefore, there are limitations to this study. First, the existence of a claim for a filled prescription does not indicate that the medication was consumed or was taken as prescribed. Second, the presence of an HCV diagnosis code 
on a medical claim is not necessarily positive presence of disease, whereby the sensitivity and specificity of the codes are unknown. Third, some information that could affect study outcomes was not available, such as certain clinical and disease-specific parameters. Fourth, prescriptions obtained outside the health care system would not have been reflected in the claims data. Fifth, an assessment of adherence to RBV was not included in the current study due to factors such as dosing and sample pills. Sixth, HCV patients included in the MarketScan and Optum databases may be different from the general HCV population.

In conclusion, the present real-world study of $\mathrm{HCV}$ infected patients showed that the addition of RBV to SOF + SIM therapy had an impact on composite adherence for SOF and SIM in patients enrolled in the MarketScan database, but not in the Optum database. The difference in composite adherence rates for SOF and SIM in the SOF + SIM cohort vs the SOF + SIM + RBV cohort in the MarketScan database was only $3 \%$; therefore, the difference may not be clinically significant. The impact of RBV on SOF adherence was not significant in either database. Further studies investigating the impact of increased pill burden on treatment adherence in HCV therapy will be of value.

\section{Acknowledgments}

The design and financial support for this study were provided by AbbVie Inc. AbbVie Inc. participated in data analysis, interpretation of data, review, and approval of the abstract.

\section{Disclosure}

TRJ, SRM, YJ, and VS are employees of AbbVie and own AbbVie stock. DRW was an employee at time of study and owns AbbVie stock. The authors report no other conflicts of interest in this work.

\section{References}

1. World Health Organization (WHO) [webpage on the Internet]. Hepatitis C fact sheet no 164. Geneva: WHO; 2014. Available from: http://www.who. int/mediacentre/factsheets/fs164/en. Accessed November 13, 2014.
2. Seeff LB. Natural history of chronic hepatitis C. Hepatology. 2002; 36(5 Suppl 1):S35-S46.

3. Chak E, Talal AH, Sherman KE, Schiff ER, Saab S. Hepatitis C virus infection in USA: an estimate of true prevalence. Liver Int. 2011;31(8):1090-1101.

4. Denniston MM, Jiles RB, Drobeniuc J, et al. Chronic hepatitis C virus infection in the United States, National Health and Nutrition Examination Survey 2003 to 2010. Ann Intern Med. 2014;160(5):293-300.

5. Olysio (simeprevir) prescribing information. Titusville, NJ: Janssen Therapeutics; Dec 2013.

6. Schinazi R, Halfon P, Marcellin P, Asselah T. HCV direct-acting antiviral agents: the best interferon-free combinations. Liver Int. 2014; 34 Suppl 1:69-78.

7. Sovaldi ${ }^{\circledR}$ (sofosbuvir) [prescribing information]. Foster City, CA: Gilead Sciences, Inc.; 2013.

8. Lawitz E, Sulkowski MS, Ghalib R, et al. Simeprevir plus sofosbuvir, with or without ribavirin, to treat chronic infection with hepatitis $\mathrm{C}$ virus genotype 1 in non-responders to pegylated interferon and ribavirin and treatment-naive patients: the COSMOS randomised study. Lancet. 2014;384(9956):1756-1765.

9. Janssen Therapeutics [webpage on the Internet]. Olysio ${ }^{\circledR}$ (simeprevir) gains additional FDA approval as once-daily, all-oral interferon- and ribavirin-free treatment option in combination with sofosbuvir for adults with genotype 1 chronic hepatitis C infection. Titusville, NJ: Janssen Therapeutics; 2014. Available from: http://www.janssentherapeutics. com/news-center/11052014pr. Accessed December 4, 2014.

10. American Association for the Study of Liver Diseases (AASLD) and Infectious Diseases Society of America (IDSA) [webpage on the Internet]. Recommendations for testing, managing, and treating hepatitis C. Available from: http://www.hcvguidelines.org/full-report-view. Accessed November 22, 2014.

11. Koh C, Heller T, Haynes-Williams V, et al. Long-term outcome of chronic hepatitis $\mathrm{C}$ after sustained virological response to interferonbased therapy. Aliment Pharmacol Ther. 2013;37(9):887-894.

12. McHutchison JG, Manns M, Patel K, et al; International Hepatitis Interventional Therapy Group. Adherence to combination therapy enhances sustained response in genotype-1-infected patients with chronic hepatitis $\mathrm{C}$. Gastroenterology. 2002;123(4):1061-1069.

13. CVS Health. Analysis of "real world" sovaldi (sofosbuvir) use and discontinuation rates. Woonsocket, RI: CVS Health; 2014. Available from: http://www.cvshealth.com/sites/default/files/hepatitisCutilization. pdf. Accessed November 13, 2014.

14. Juday TR, Baran RW, Manthena SR, Walker DR. Impact of pill count on medication adherence during the first 12 weeks of HIV antiviral treatment: implications for $\mathrm{HCV}$ treatment. Poster presented at: EASL 50th The International Liver Conference 2015; April 22-26, Vienna, Austria.

15. Koh C, Liang TJ. What is the future of ribavirin therapy for hepatitis $\mathrm{C}$ ? Antiviral Res. 2014;104:34-39.

16. Clark V, Nelson DR. The role of ribavirin in direct acting antiviral drug regimens for chronic hepatitis C. Liver Int. 2012;32(Suppl 1): 103-107.
ClinicoEconomics and Outcomes Research

\section{Publish your work in this journal}

ClinicoEconomics \& Outcomes Research is an international, peerreviewed open-access journal focusing on Health Technology Assessment, Pharmacoeconomics and Outcomes Research in the areas of diagnosis, medical devices, and clinical, surgical and pharmacological intervention. The economic impact of health policy and health systems

\section{Dovepress}

organization also constitute important areas of coverage. The manuscript management system is completely online and includes a very quick and fair peer-review system, which is all easy to use. Visit $\mathrm{http}: / /$ www.dovepress.com/testimonials.php to read real quotes from published authors. 